\title{
Influence of structural and textural features of ores and rocks on mine dust explosion hazard during development of pyrite deposits
}

\author{
Marina Rylnikova ${ }^{1 *}$, Viktor Fedotenko ${ }^{1}$, and Natalia Mitishova ${ }^{1}$ \\ ${ }^{1}$ Federal State Budgetary Institution of Science - Institute of Comprehensive Exploitation of Mineral \\ Resources named after academician N. V. Melnikov of the Russian Academy of Sciences, 111020, \\ Moscow, Russia
}

\begin{abstract}
In the practice of mining works, sulfide-dust explosions often occur during underground development of pyrite ore deposits: copper-zinc, lead-zinc, copper-nickel, antimony, and others. This makes it necessary to conduct researches aimed at improvement of methods for studying the explosive properties of sulfide dust and development of industrial and environmental safety requirements for mining operations. Currently, there is no generally accepted state-approved regulatory procedure for assessment of sulfide dust explosion hazards during underground mining operations in Russia. Assessment of the type and concentration of mine sulfide dust in the underground mine atmosphere is vitally important for solving this problem. In practice, ores even with a sulfur content of less than $35 \%$ can constitute a sulfide dust explosion hazard, although mine dust with a sulfur content of less than $35 \%$ does not explode in laboratory conditions. To identify the cause of this phenomenon and develop technical solutions for ensuring safety of underground mining operations, change in the sulfur content of various mine dust fractions obtained from primary disintegration of sulfides was studied.
\end{abstract}

Keywords: sulfide dust, fractional composition, explosion, underground mining, sulfur, sulfide minerals, structure, factors, safety.

\section{Introduction}

The relevance of this research is justified by the role of pyrite ore deposits with non-ferrous and precious metals in the mineral resource balance of Russia. For example, during copper mining in Russia, sulfide-copper-nickel ores comprise 52\%, copper-pyrite ores - 34\% according to the geological and industrial type of ores [1]. In total for the sulfide-coppernickel and copper-pyrite ore types, the potential resource base of Russia is represented by $53 \%$. Thus, deposits of sulfide-copper-nickel and copper-pyrite types are the basis of the country's reserves structure, as well as the Russian copper-mining industry [2].

In addition, a significant share of the Russian gold reserves is concentrated in the complex-deposit ores, which are dominated by copper-pyrite and sulfide-copper-nickel. The gold-sulfide-quartz type of ores has a significant part in the total reserves of Russia [1]:

*_Main author:_rylnikova@mail.ru 
including $26 \%$ are already being extracted, and $43 \%$ comprise the Russian resource potential.

It is obvious that Russia holds a leading position in the sulfide ore reserves, which are among the strategic ones, and the scale of their extraction and subsequent production prospects require creation of the conditions ensuring the mining operation safety by reducing the probability of sulfide-dust explosions.

With regard to the identified problem of sulfide dust explosions during underground development of pyrite ore deposits, the current trends of changing the underground mining process were considered. It was established that over the past decade there has been a significant growth of dust generation in the underground conditions, caused by the increase in intensity of drilling and blasting works associated with depletion of the Russian mineral resources base [3] and transition to mining of the poorer sulfide ores.

These changes led to the need for a comprehensive assessment of mineralogical and phase composition of sulfide dust with regard to the material composition and structure of ores and enclosing rocks. For an adequate assessment of the sulfide dust explosion hazard, studies expanding knowledge about the sulfide dust properties and allowing assessment of the sulfide dust explosive risks were carried out.

\section{Experimental research methods}

Overview of the issue under study [4-5] shows that ores even with a sulfur content of less than $35 \%$ can often pose a sulfide dust explosion hazard in the field [6-7], although mine dust with a sulfur content of less than $35 \%$ does not explode under laboratory conditions. To identify the cause of this phenomenon and develop technical solutions aimed at ensuring safety of underground mining operations, change in the sulfur content of various mine dust fractions obtained from primary disintegration of sulfides was studied. For this purpose, the study hypothesized that an uneven sulfur distribution occurs in different size classes during crushing due to primary destruction of sulfide ore. This clarification is of crucial importance, as it allows evaluating similar results of primary crushing after blasting operations in the conditions of underground sulfide ore mining and determining the nature of sulfur content distribution depending on the size of the crushed dust particles.

To test this hypothesis, in the laboratory for environmentally sustainable exploitation of mineral resources in the Institute of Comprehensive Exploitation of Mineral Resources (Russian Academy of Sciences), a study which included sulfur content measurement for sulfide ores of various size classes obtained from primary crushing of sulfides was carried out.

Low-sulfide ores and rocks from the Sentachan and Shanuch deposits, as well as rocks with a high sulfur content taken from the Sibayskoye deposit were used as test samples.

Sample preparation included preparing of geological sections and mineral composition analysis of the ore and rock samples; crushing of samples using a laboratory jaw crusher to a fraction of $-5-0 \mathrm{~mm}$; the resulting material was crushed to a size of $-250-0$ microns using the VKMD10 laboratory cone crusher; fractions for all types of samples were prepared using the EML 200 sieving machine, the sizes were $-40 ;-71+40 ;-100+71 ;-125+100$; $160+125 ;-200+160 ;-250+200$ microns. To do this, the material was loaded into sieves of the sieving machine, the sieving time was 40 minutes, the sieving interval - 10 minutes, the amplitude $-2 \mathrm{~mm}$; for X-ray fluorescence analysis, samples of each fraction were put in special cuvettes and covered with a film.

Further research included sulfur content determination in the samples of various size classes by X-ray fluorescence analysis using the Olympus X-5000 Mobile XRF device, as well as study of textural and structural features of the ore and rock samples by optical microscopy method. 


\section{Results and discussions}

The sulfur-pyrite rock of the Sibayskoye deposit (sample marking No.1) is a dense mineral pyrite aggregate. It has pores of different sizes and configurations. Change in the sulfur content by size class is shown in Figure 1.

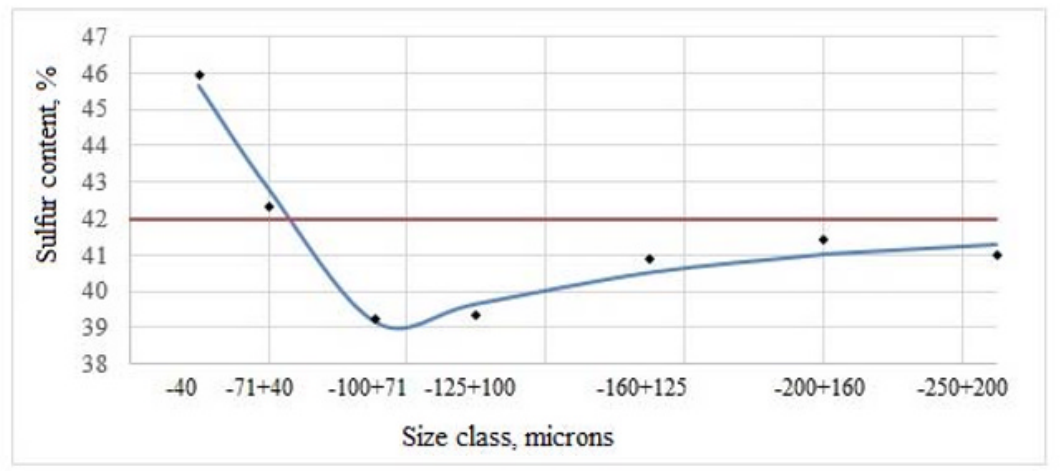

Fig. 1. Sulfur content in various size classes of the sulfur-pyrite rock from the Sibayskoye deposit (sample No.1)

The graph shows that the smallest ore fractions obtained as a result of primary disintegration are characterized by high sulfur content. The minimum sulfur content for the fraction $-100+71$ microns is $-39.13 \%$, the maximum value was recorded when the particle size was less than 40 microns. At the same time, the sulfur content in the fractions -40 microns and $-100+71$ microns differ by $6.53 \%$, which is $15.54 \%$ relative to the average content of the sample. As the particle size increases more than 100 microns, sulfur content in the sulfur-pyrite ore is close to the average value.

To determine the nature of the detected sulfur content distribution, the ore samples were studied by optical microscopy method. As a result, it was found out that ore composition of sample No.1 is massive, with a noticeable fracturing. Mineral composition of sulfur-pyrite ore: the main ore-forming mineral is pyrite; the secondary ore-forming mineral is sphalerite.

The shape of pyrite segregations is round or oval. Lace aggregates form a transparent weaving of fine-grained pyrite. Framboidal pyrite is characterized by round segregations with a honeycomb-like internal structure. It occurs in the form of dispersed formations or their clusters in the central parts of reniform pyrite aggregates. The size of pyrite microcrystal clusters does not exceed 20-100 microns.

Sphalerite forms xenomorphic segregations in the central part, along radial and concentric cracks or even separate zones in pyrite reniform and lace aggregates.

Additional studies were conducted to find out relationship between the ore microstructure and the sulfur distribution nature by fractions after primary crushing.

The copper-pyrite ore of the Sibayskoye deposit (sample No.2) is a dense mineral pyrite aggregate with uniform copper mineralization. Mineral composition: main ore-forming mineral is pyrite; secondary minerals are chalcopyrite and sphalerite. Pyrite forms the main mass of copper pyrites. The form of sulfur pyrite segregations is coarse-grained aggregates, there are pyrite recrystallization zones with generation of well-formed crystals in the form of hexahedron sections. The pyrite grain sizes vary over a wide range - up to 100 microns or more.

Chalcopyrite closely associates with pyrite and is represented by allotriomorphic segregations, whose shape is determined by different configurations of pores, crack 
cavities, interlayer space and interstices of granular pyrite aggregates. The size of chalcopyrite reaches more than 250 microns.

Sphalerite is present in subordinate quantities. It occurs in the form of xenomorphic segregations in the ore, creating cavities of pore cracks in the pyrite aggregate.

Change of sulfur content in different size classes was studied for copper-pyrite rock in sample No. 2 from the Novy Sibay deposit, the results are shown in figure 2 .

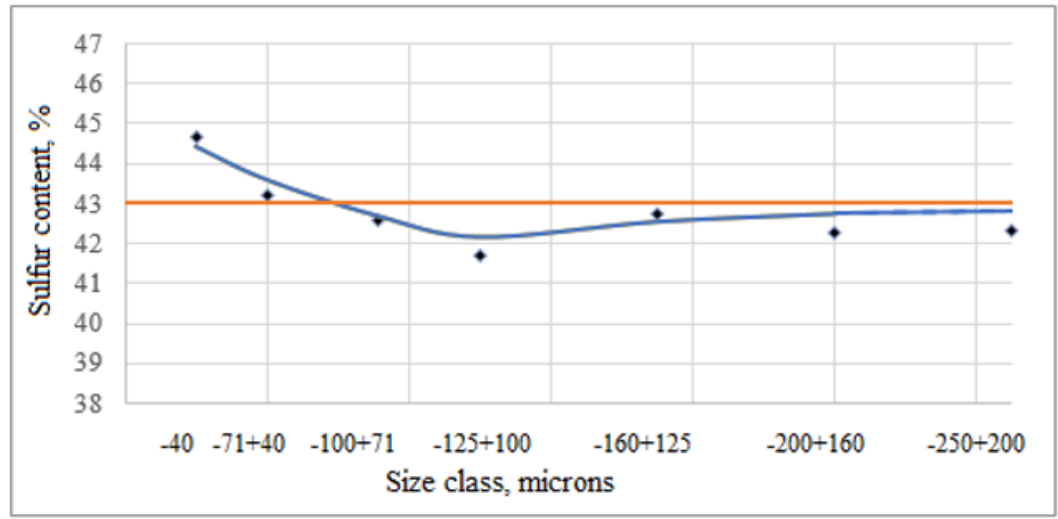

Fig. 2. Changes of the sulfur content in different size classes of copper-pyrite rocks from the Sibayskoye deposit (sample No.2)

The graph shows that sample No.2 is characterized by a slight variability in the sulfur content of various ore fractions crushed during the primary crushing, and deviations from the average content are about $5 \%$.

In the fragments of quartz-antimony ore from the Sentachan deposit (sample No.3), the ore mineral composition is represented by quartz $(35-45 \%)$ and antimony $(55-65 \%)$. Arsenic pyrite is present in sample No.3 in subordinate quantities. Massive ores are composed of fine-grained antimony, the recrystallization structure areas characterized by granoblastic structure can be traced. The grain size is 10-50 microns.

Internal structure of the antimony grains is characterized by twinning structures, expressed by broad development of antimony plates, probably associated with natural deformations. It should be noted that alternation of grains with twinned structure and without it can be observed in the massive mineral aggregates.

For quartz antimony ores of the Sentachan deposit, research results of the sulfur content changes in different size classes are shown in Figure 3.

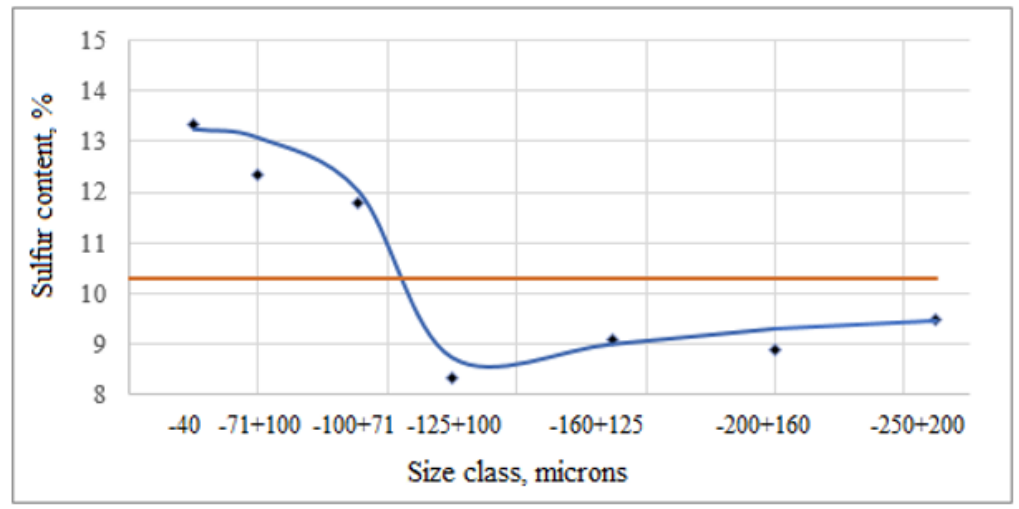

Fig. 3. Changes of the sulfur content in different size classes of sulfur-pyrite ore from the Sentachan deposit (sample No.3) 
The presented graph suggests that the tested sample is characterized by significant variability of the sulfur content in various fractions of ore crushed during primary crushing. For a fraction of -40 microns, the sulfur content is by $2.9 \%$ higher than the sample average, which is $28.34 \%$ in relative terms. At the same time, the sulfur content in the fractions -40 microns and $-125+100$ microns differ by $4.49 \%$, which is $43.56 \%$ relative to the average content of the sample.

In sample No. 4, taken from the Shanuch deposit and represented by granite-gneisses, gabbro and impregnated ores, the rock part is composed of amphibole, chlorite, quartz, feldspar, serpentine, carbonate. Chalcopyrite is the second most common ore mineral in sample No.4, its content reaches $6 \%$. It is present in the form of xenomorphic segregations in the ore, creating impregnations in pyrite and independent fields.

The sulfides in sample No.4 form single impregnations with a uniform distribution in porphyric formations of hydromicaceous aggregates. The size of the impregnations does not exceed 20 microns. In the sample, thickening of impregnations with formation of spots can also be seen, larger segregations of pyrite -40 microns, chalcopyrite -200 microns and violarite - 100 microns prevail there.

Mineralogical studies of sample No. 4 showed that vein-disseminated ores, sulfide mineralization is represented by pyrite, chalcopyrite and violarite with the uneven distribution pattern.

For sample No.4 from the Shanuch deposit, changes of the in different size classes are shown in Figure 4. sulfur content.

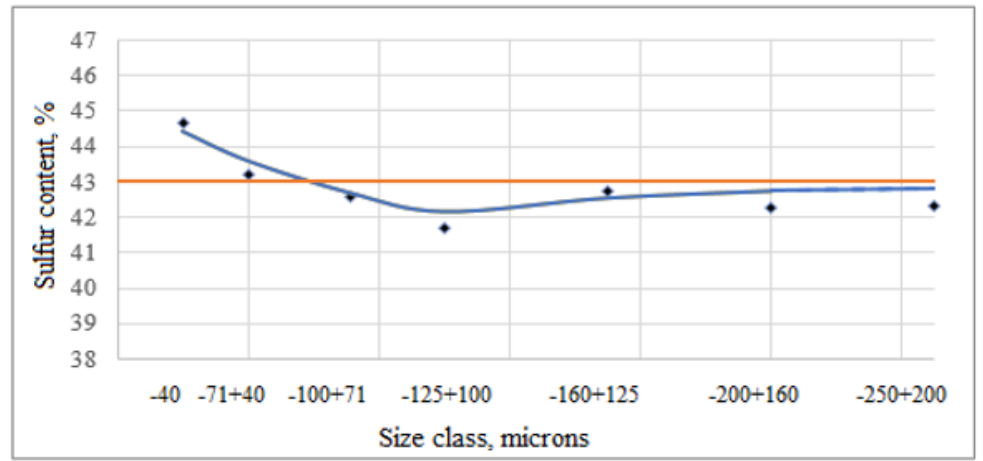

Fig. 4. Changes of the sulfur content in different size classes of the Shanuch deposit ore represented by granitic gneisses (sample No.4)

The effect of sulfur content redistribution between the ore fractions during its primary crushing is observed. The ore is fine and medium-grained, as can be seen from the graph, for the fraction of -40 microns, the sulfur content is by $1.67 \%$ higher than the sample average, which is $11.13 \%$ in relative terms. At the same time, the sulfur content in the fractions -40 microns and $-125+100$ microns differ by $3.11 \%$, which is $20.7 \%$ relative to the average content of the sample.

The established regularity of sulfur content redistribution in various fine-grained ores and rocks suggests that when sulfur minerals have lower brittleness and hardness, in contrast to the associated ones, sulfides will be firstly exposed to crushing, which involves explosion risk of the sulfur dust containing sulfur in quantities sufficient for exothermic reaction development.

It should be noted that sulfide minerals are more often characterized by increased brittleness, for this reason they are more prone to dust generation during mechanical actions like drilling and blasting destruction. 


\section{Conclusions}

As follows from analysis of the results obtained during measurement of the sulfur content for various size classes after primary crushing of ores from the Sibayskoye, Sentachan and Shanuch deposits and sample examination by optical microscopy method, it was found that:

1. Increased sulfur content in small fractions of -40 microns is typical for ores characterized by a fine-grained, impregnated structure. As the size of the dust fractions under study increases $-71+40 ;-100+71 ;-125+100 ;-160+125 ;-200+160 ;-250+200$ microns, the sulfur content is closer to the average value of the sample. Therefore, in finegrained ores with an impregnated structure during re-crushing and forming of small fractions as part of various technological processes, the probability of explosive dust cloud formation is higher than in coarse-grained massive ores and rocks.

2. Structure of the sulfur-bearing minerals, namely, its grain size, determines possible increase of sulfur content in the fractions with particle size less than 40 microns formed after primary ore destruction, and consequently the potential fire hazard of sulfide dust with the average sulfur content below $35 \%$.

3. A slight change in the sulfur content by fractions formed as a result of primary crushing is typical for rocks characterized by coarse-grained, massive structure.

4. Given that sulfides are mainly brittle minerals, in the drilling, blasting, falling and primary disintegration processes of rocks, sulfide minerals with the highest brittleness will be subject to greater destruction, which leads to an increase of sulfur distribution in the dust aerosols and is particularly dangerous during development of sulfide deposits.

5. The following were analyzed in the course of geological and mineralogical assessment: mineral composition of ores and rocks, brittleness and hardness of minerals, grain size of the sulfides and their occurrence form, regularities of crystallographic structure clarity of sulfides were determined. All of this has a significant impact on the nature of sulfur content distribution during disintegration of ores and rocks in different size classes of dust fractions.

Importance of the established sulfur redistribution pattern during disintegration of sulfide ores and rocks into smaller fractions takes on particular significance, given the increase of production capacities and involvement of ores with low content of useful components in the mining process. Intensification of mining operations entail a significant growth of the intensity and volumes of dust generation due to increase in the number of blast-hole and well drilling, amount of fired ore mass, implementation of mobile load-haul transport that have become a new source of dust in the underground conditions, increase in the volume of the rock mass moved under its own gravity.

\section{References}

1. State report on the status and usage of mineral resources of the Russian Federation in 2018 (2019)

2. V.B. Kondratiev, V.V. Popov, V.G. Kedrova. Mining Industry, 3 (145), 80 (2019)

3. D.R. Kaplunov, D.N. Radchenko, Mining Inf. Anal. Bull, S1, 165 (2017)

4. M. V. Rylnikova, N. A. Mitishova, Mining Inf. Anal. Bull, 9, 41 (2019)

5. M. V. Rylnikova, N. A. Mitishova, Ponomarev A.P. Proceedings of the Tula States University-Sciences of Earth, 3, 97 (2019)

6. Y.Z. Rao, C. S.Tian, W. Xu, Xiao, C.Y.; Yuan, B.Y.; Yu, Y. Journal of Chemistry, 12, 7980403 (2020)

7. Safety management of underground combustible sulfide dust (Guideline. Department of Industry and Resources, MOSHAB, 1997) 